\title{
The problem of winter crossing the Lena River in the Republic of Sakha (Yakutia)
}

\author{
Grigory Nektegyaev ${ }^{1, *}$ and Elena Kardashevskaya ${ }^{1}$ \\ ${ }^{1}$ North-Eastern Federal University, 58, Belinsky str., Yakutsk, Republic of Sakha (Yakutia), Russia, \\ 677027
}

\begin{abstract}
The study of the organization of the crossing of the Lena River during the winter period revealed a number of problems: the presence of unauthorized places for the organization of traffic spontaneously organized by the population, low freezing temperatures, breach of regulations for the carrying capacity of vehicles, overrunning, the use of winter roads after their closure. In providing crossing it is advisable to recommend conducting briefings with drivers and pedestrians on the rules for the safe operation of winter roads in order to eliminate the identified deficiencies and security upgrade. Drivers are required to prepare vehicles in advance, have warm clothes, spare batteries for mobile devices, and first aid kit. This is necessary to hold out until help arrives in the case of an emergency.
\end{abstract}

\section{Introduction}

The availability of fuel-efficient transport routes is traditionally a serious problem for the Republic of Sakha (Yakutia). If in the summer months ferries operate on the Lena River, winter roads are laid in the winter, then in the off-season whole areas are cut off from the capital of the region, without the possibility of full-fledged purchases of food commodity, medicines and other goods necessary for the population. Barges, concentrated primarily in Yakutsk, become the main means of delivery, so the delivery process takes 3-7 days or even more in the summer months. In this work, using the methods of continuum mechanics, the process of destruction of the ice cover under the action of detonation products has been studied [1].

Transport logistics issues play a paramount role for Yakutsk, since the full-flowing the Lena River breaks the existing transport chains for the delivery of goods and passengers. The overwhelming majority of the goods needed to meet the needs of the local population in the region is delivered by road, but it in increasingly short supply the necessary infrastructure [2].

In case of severe frosts, breakdowns of vehicles directly at the crossings are not excluded in winter. The desire to load cars to the maximum leads to their overloading and an increase in the risk of accidents, about which the employees of the Ministry of Emergency Situations regularly warn carriers, and also use rescuers for watchstanding in the most dangerous areas.

\footnotetext{
* Corresponding author: gnektegyaev@mail.ru
} 
The ice crossing is a fragment of a road broken on the ice of a river (other water body) for the purpose of movement of automobile or horse-drawn vehicles and people in the framework of meeting the needs of the population and economic entities.

The winter road is a seasonal road designed for operation in winter frost conditions. During arranging winter roads, snow is tamped with graders, ice crossings on water bodies are frozen. As a result, a winter road can be organized directly on rivers and lakes after they freeze.

Winter roads are an important seasonal element of the transport infrastructure in Yakutia. In total, 41 such roads with a total length of 8112,24 kilometers operate in the region.

One of them is capable of withstanding loads of up to 40 tons, 17 winter roads each are designed for the movement of vehicles up to 20 and 30 tons respectively. For the rest of the winter roads, the maximum carrying capacity varies within 5-15 tons [3].

\section{Research methods and principles}

In the process of carrying out the research work, the following methods were used:

- General scientific method, providing for the analysis of the existing scientific literature on the issue.

- An empirical method that involves observing what is happening.

- A theoretical method involving the analysis of the data obtained.

The descriptive method, which involves observing the subject of research and analyzing the data obtained from its results, was the basis for this research work.

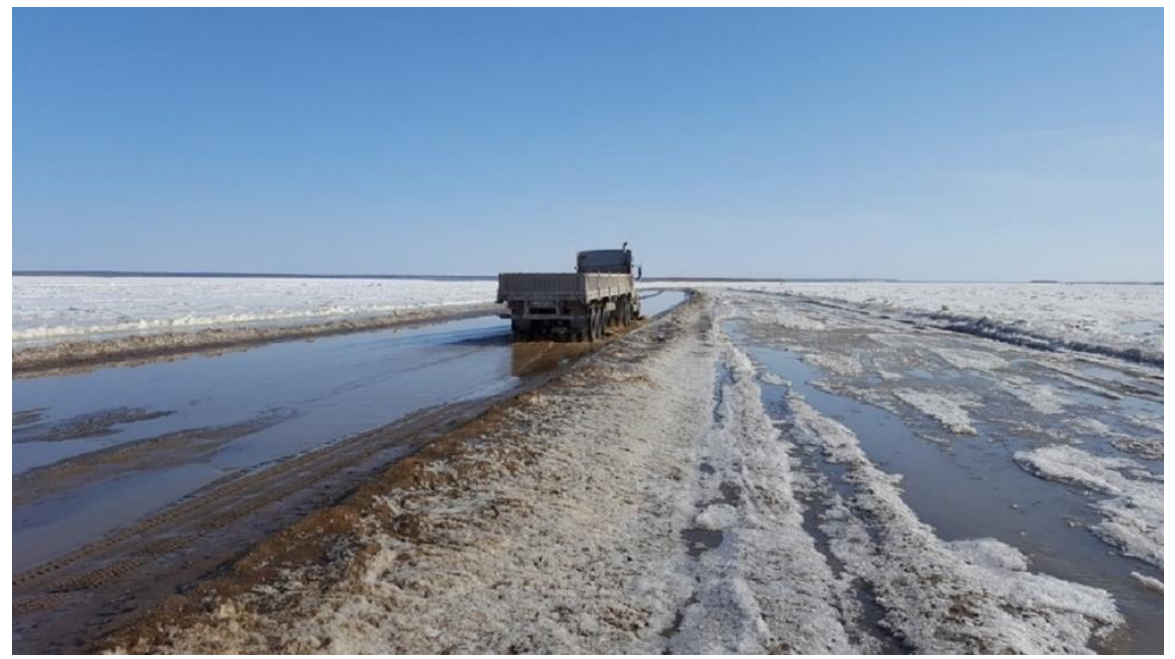

Fig. 1. Ice crossing "Yakutsk-Nizhny Bestyakh".

The ice crossing is a auto-road arranged on an ice-covered river, organized in the absence of a bridge crossing, and also due to the impossibility of arranging a ferry crossing in winter due to the formation of an ice cover on water bodies [4].

The main reason for accidents at crossings are vehicle defects, their overload, exceeding the maximum speeds of movement, weather conditions.

The northern regions of Yakutia can be reached by land exclusively in winter [5].

In order to prevent accidents at the crossings, mobile units of rescuers of the Ministry of Emergency Situations are on duty.

During the process of preparing the crossing, the thickness and strength of the ice are 
taken into account, while the minimum distance between the lanes is 100 meters. Ice thickness measurements are carried out by drilling holes on the sides of the road with a diameter of 60-100 mm (Figure 2).

In case of insufficient ice thickness, ice build-up is carried out. For this reason, additional formwork is installed with water filling of the required thickness. After the completion of "freezing of water" on the road, the necessary road signs and lighting are installed, if possible.

There are standard methods to improve the performance and reliability of the ice crossing: reinforcement with wooden track decking, freezing the ice from the bottom or from the top [6].

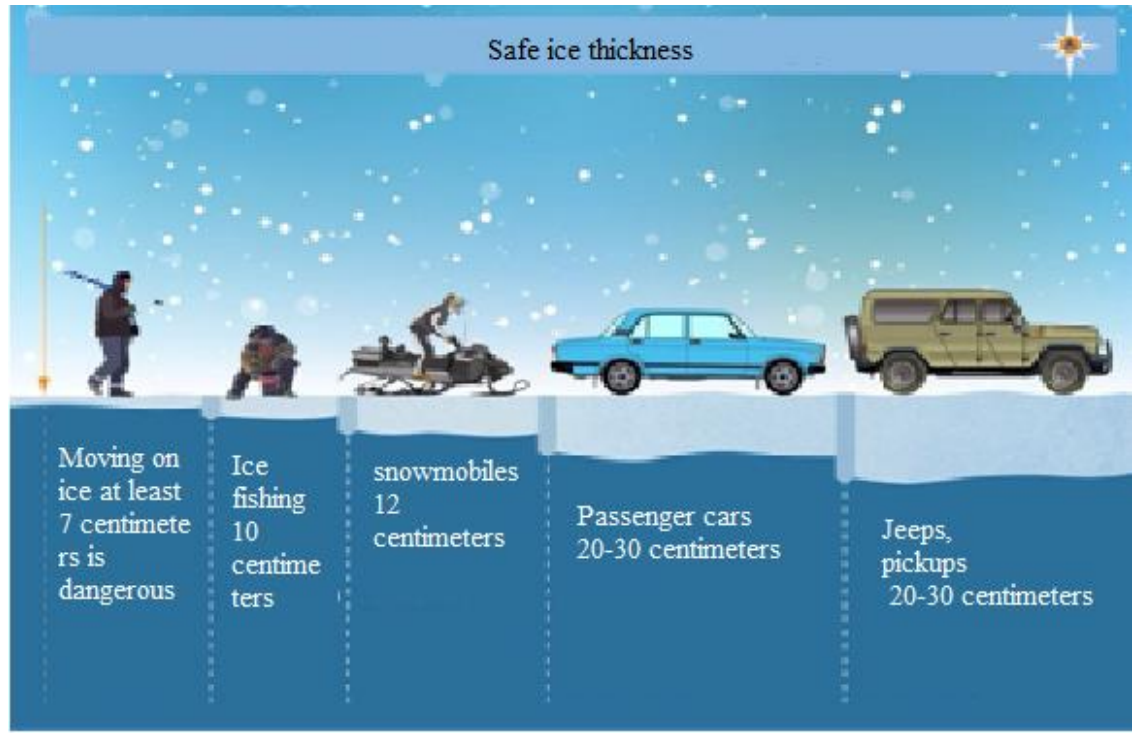

Fig. 2. Safe ice thickness.

The use of reinforcing frames made of various composite materials leads to a significant increase in the bearing capacity of ice [7].

The existence of the bridge cross the principal waterway of the region must change the traffic situation drastically, having united several traffic roads of federal importance including "Lena", "Kolyma", "Vilyui". The bridge shall provide the construction of the shortest traffic road from East Siberian regions to the harbors located on the shore of the Sea of Okhotsk. In its entirety the project is of paramount importance to the whole Eastern Siberia. In the future it may become one of the elements of the transcontinental route scheme from Asia-Pacific region to European countries.

The existence of the bridge may solve many a problem of Yakutia residents. Also it may stimulate economic growth in the region. According to the preliminary calculations flow of cargo will be increased to 6 million tons, the number of carry passengers will grow to 8 million. Only within organization of north delivery the bridge will allow to cut corners on carriage costs up to 4 billion rubles on an annual basis.

There will be stimulated economic growth in combination with creation of additional jobs. According to the experts' calculations the GDP growth shall be 3\% annually due to the existence of the bridge, while the obtained positive effects will cover construction costs by 1.6 times.

The Lena offers rough building conditions including high speed of the current, mighty ice drift with its sickness up to $2.5 \mathrm{~m}$, severe overflow in early spring. As a result there will be used a pylon model of construction, where each pylon will turn into so-called icebreaker. 


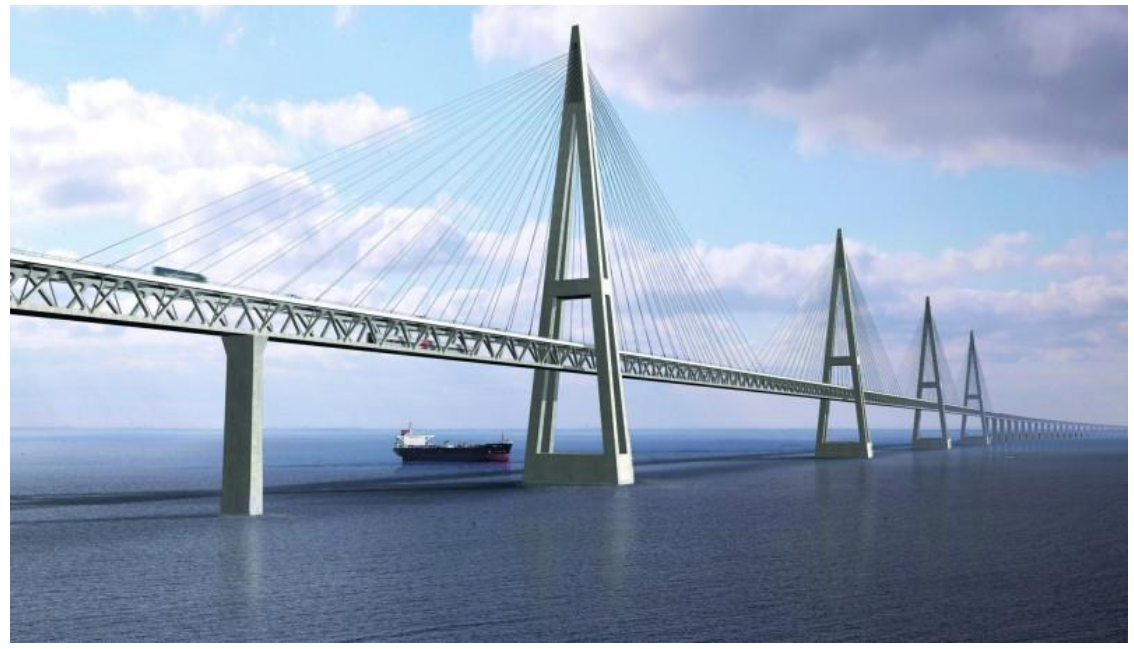

Fig. 3. The project of the bridge cross the Lena.

Bridge properties:

- $\quad$ Category of the road -2

- $\quad$ Span $-3.1 \mathrm{~km}$

- $\quad$ Length of automobile approach roads $-10.9 \mathrm{~km}$

- Number of pathways -2

- Traffic capacity per day -7 thousand of cars

- $\quad$ Structure - pylon cable-stayed.

The length of each pylon is $247 \mathrm{~m}$, the length of span between them is $840 \mathrm{~m}$.

Project life cycle:

- 2019 - conclusion of the concessionary agreement and including the building activity to the programme of development on transportation infrastructure.

- 2020-2021 - conduct of the projects operations concerning the project.

- 2021-2025 - direct bridge building.

- 2025 - turnover to operations (fig. 3).

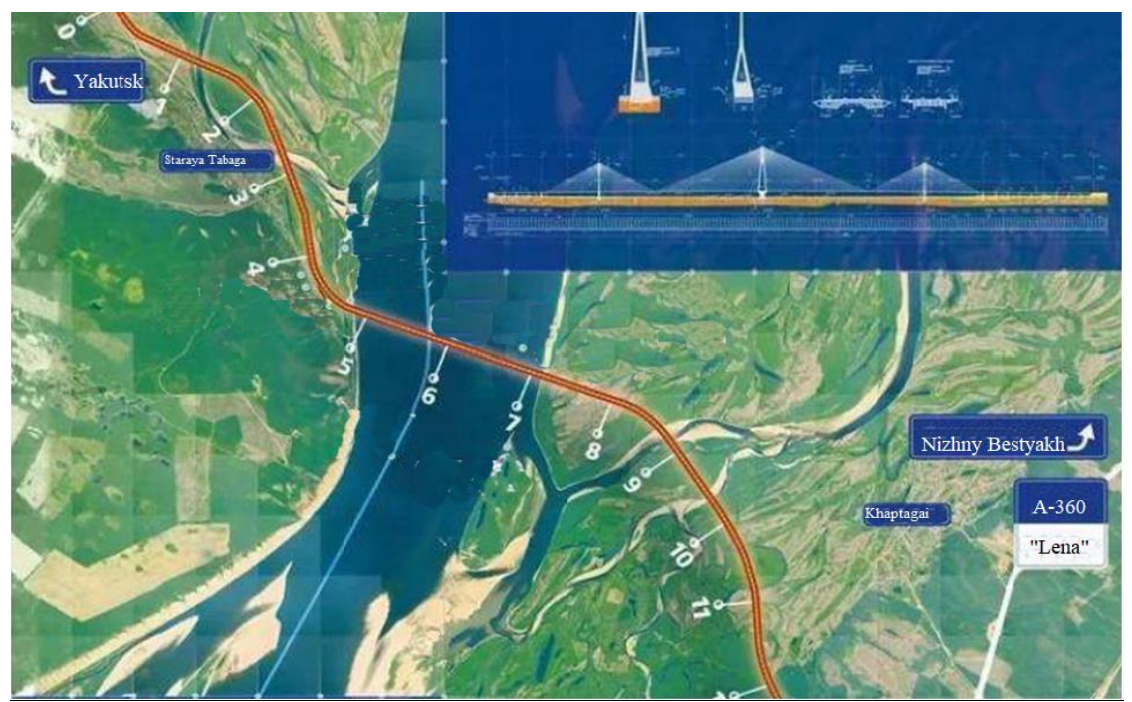

Fig. 4. The map of the Lena bridge. 
For the present time there were obtained soil samples in the places of bridge pillars. Also there are held bank investigations, analyzed satellite images of the bridge site for developing the digital surface model.

The direct process of bridge building will be held through the cooperative efforts of "Rostec" corporation and VIS. The state governments register high-efficiency of addressing the issue in terms of mechanical solutions as well as economic justification of the project.

The bridge will connect two villages Staraya Tabaga and Khaptagai on the sides of the Lena. Its length will be $3.12 \mathrm{~km}$, the stretch of necessary approach road is $10.9 \mathrm{~km}$. The whole project value is rated at $83.4 \mathrm{~b}$ rubles, where the government allocated $54.3 \mathrm{~b}$ rubles. The capital asset is to be attracted by the private partner.

The negative influence upon the building activity is the absence of year around transport connection in Yakutsk region. For the first time ever the bridge building cross the Lena in Yakutsk was discussed for the soviet union time yet, namely at $80 \mathrm{~s}$, but the practical realization the project was achieved only in our days.

It is taken into account seismic activity in the region too. Despite the deep-frozen soil there has been noted the continental plate activity in Yakutsk region. The result of their moves are the recurrent earthquakes, however their magnitude is not powerful enough for people to feel the earth tremors. Nevertheless, having done the structural analysis this particular fact is to be taken into consideration.

\section{Acknowledgement}

I, Grigory Grigorievich Nektegyaev, want to express my sincere gratitude to my scientific supervisor, Elena Georgievna Kardashevskaya, for his help in finding the sources of literature that became the basis for writing this scientific article.

\section{References}

1. A.S. Vasiliev, V.L. Zemlak, V.M. Kozin, Mechanics of deformable solid body, 128-30 (2020)

2. L.N. Gotovtseva, A.I. Borisov, Economics and Enterprise 11(124), 1234-7 (2020)

3. The timing of the opening of winter roads in Yakutia has been shifted, https://mintrans.sakha.gov.ru/news/front/view/id/3244228-2020-HTML.html

4. A.A. Trapeznikov, I.L. Bartolomey, Building and construction. Architecture 2, 64-72 (2019)

5. A.A. Suleymanov, Transparent History. Historical sciences 1(15), 60-4 (2019)

6. K.I. Ipatov, A.S. Vasilev, V.L. Zemlyak, Physics 1, 98-105 (2019)

7. K.I. Ipatov, A.S. Vasilev, V.L. Zemlyak, E.V. Leskov, Mechanics 3(40), 3-12 (2019)

8. Safe ice thickness for human and winter crossing, https://fireman.club/statyipolzovateley/bezopasnaya-tolshhina-lda-dlya-cheloveka-i-zimney-perepravyi/ 2017HTML.html

9. Icy road "Yakutsk - Nizhny Bestyakh", https://www.vesti14.ru/2020/04/09/ledovayapereprava-yakutsk-nizhnij-bestyah-zakroetsya-s-16-aprelya/ -2020-HTML.html

10. Insidious winter roads: how roads are built from snow and ice in the Far North and what danger they pose in themselves, https://5koleso.ru/avtopark/kovarnye-zimnikikak-na-krajnem-severe-stroyat-dorogi-iz-snega-i-lda-i-kakuyu-opasnost-oni-v-sebetayat/ -2020-HTML.html 